\title{
Statistical approach to optimize production of biosurfactant by Pseudomonas aeruginosa 2297
}

\author{
Arthala Praveen Kumar • Avilala Janardhan • \\ Seela Radha • Buddolla Viswanath • \\ Golla Narasimha
}

Received: 4 December 2013/Accepted: 17 February 2014/Published online: 8 March 2014

(C) The Author(s) 2014. This article is published with open access at Springerlink.com

\begin{abstract}
The main objective of this paper is to optimize biosurfactant production by Pseudomonas aeruginosa 2297 with statistical approaches. Biosurfactant production from P. aeruginosa 2297 was carried out with different carbon sources, and maximum yield was achieved with sawdust followed by groundnut husk and glycerol. The produced biosurfactant has showed active emulsification and surfaceactive properties. From the kinetic growth modeling, the specific growth rate was calculated on sawdust and it was $1.12 \mathrm{day}^{-1}$. The maximum estimated value of product yield on biomass growth $\left(Y_{\mathrm{p} / x}\right)$ was $1.02 \mathrm{~g} / \mathrm{g}$. The important medium components identified by the Plackett-Burman method were sawdust and glycerol along with culture parameter $\mathrm{pH}$. Box-Behnken response surface methodology was applied to optimize biosurfactant production. The obtained experimental result concludes that Box-Behnken designs are very effective statistical tools to improve biosurfactant production. These results may be useful to develop a high efficient production process of biosurfactant. In addition, this type of kinetic modeling approach may constitute a useful tool to design and scaling-up of bioreactors for the production of biosurfactant.
\end{abstract}

Keywords Pseudomonas aeruginosa - Biosurfactant . Kinetic growth modeling · Plackett-Burman - Response surface methodology (RSM)

Electronic supplementary material The online version of this article (doi:10.1007/s13205-014-0203-3) contains supplementary material, which is available to authorized users.

A. P. Kumar · A. Janardhan - S. Radha · B. Viswanath .

G. Narasimha $(\square)$

Applied Microbiology Laboratory, Department of Virology,

Sri Venkateswara University, Tirupati 517 502, India

e-mail: gnsimha123@rediffmail.com

\section{Introduction}

Microbial surfactants are structurally different group of surface-active biomolecules produced by a variety of microorganisms and are receiving considerable attention due to their unique properties such as higher biodegradability, lower toxicity, and greater stability (Mukherjee et al. 2006; Mulligan 2005). Biosurfactants are predominantly produced by bacteria, fungi, and yeasts include glycolipids, lipoaminoacids, lipopeptides, lipoproteins, lipopolysaccharides, phospholipids, monoglycerides, and diglycerides. Among these, the glycolipids produced by strains of Pseudomonas have received much attention due to their notable tensioactive and emulsifying properties (Maier and Soberon-Chavez 2000; Mulligan 2005). However, biosurfactants have limited applications owing to their high production costs, which can be lowered by process optimization, downstream processing strategies, agro-industrial waste fermentation, and use of hyper-producer strains (e.g., mutant and recombinant strains) (Wei et al. 2004; Perfumo et al. 2010). One of the methods which accomplished the above objective is the selection of suitable media components and optimal culture conditions to enhance biosurfactant productivity. The limitations of classical method of media optimization can be overcome by the application of single factor optimization process by statistical experimental design using Plackett-Burman design and response surface methodology (RSM) (Lotfy et al. 2007; Tanyildizi et al. 2005).

The Plackett-Burman design is a widely used statistical design technique for the screening of the medium components, and the variables screened by Plackett-Burman design were further optimized in a $2^{3}$ factorial Box-Behnken design methodology (Plackett and Burman 1944; Box 1952). Response surface methodology (RSM) is the 
extensively used statistical technique for media optimization and for designing experiments, evaluating the effects of factor and relative significance and searching the optimum factors related to desired response. It has the intense ability to interpret the interactive effects among input variables are some attractive features of RSM (Al-Araji et al. 2007; Montgomery 1997). In the present study, we have applied response surface methodology (RSM) to enhance the production of biosurfactant by Pseudomonas aeruginosa 2297.

\section{Materials and methods}

Test organism

Pseudomonas aeruginosa (MTCC 2297) was obtained from the microbial type culture collection (MTCC), Chandigarh, India, and it was maintained on nutrient slants at $4{ }^{\circ} \mathrm{C}$.

Examination of biosurfactant produced by Pseudomonas aeruginosa

\section{Oil spreading method and oil collapse method}

Oil spreading technique and oil collapsed method were carried out according to the method (Youssef et al. 2004).

Optimization of carbon and renewable sources

for enhanced production of biosurfactant

P. aeruginosa was cultivated in $250 \mathrm{ml}$ Erlenmeyer flasks containing $50 \mathrm{ml}$ mineral salt medium (MSM) (g/l) (Camilios et al. 2008). To this medium, different carbon sources (2\%), i.e., glycerol, glucose, coconut oil, and groundnut oil, and different renewable sources (10\%), i.e., rice bran, sawdust, groundnut husk, and wheat bran, were added and sterilized at $121^{\circ} \mathrm{C}, 15 \mathrm{lbs}$ pressure for $15 \mathrm{~min}$. After sterilization, the flasks were cooled to room temperature, and then, $2 \%$ of overnight culture was inoculated and incubated at $30{ }^{\circ} \mathrm{C}$ in an orbital shaker for 6 days. For every $24 \mathrm{~h}$, the broth was collected to analyze growth and biosurfactant production and their emulsification and surface activities.

Experimental design and statistical analysis

\section{Plackett-Burman design}

To find out the important medium components, a Plackett-Burman design was applied and it is a design of fractional plan. It allows the investigation of up to $N-1$ variables with $N$ experiments and assumes that there are no interactions between the different media components. For this study, six components were selected to evaluate their effect on biosurfactant production in 12 experiments, and surface tension was used as a response. Each column represents a different experimental trial, and each row represents different variables. Each variable was tested at two levels, a higher (+) and a lower (-) level (Table 1).

Response surface methodology

The optimized concentrations and interactions between the significant factors were identified by Plackett-Burman design and studied by using response surface methodology. RSM was used for experimental design based on the Box-Behnken design algorithm. The factors settings were tabulated (Table 3). MATLAB version 7.7.0 (R2008b) was used to create a 3 -factor Box-Behnken design. The generalized polynomial model of three factors was as follows:

$$
\begin{aligned}
Y= & \beta_{0}+\beta_{1} X_{1}+\beta_{2} X_{2}+\beta_{3} X_{3}+\beta_{12} X_{1} X_{2}+\beta_{13} X_{1} X_{3} \\
& +\beta_{23} X_{2} X_{3}+\beta_{11} X_{1}^{2}+\beta_{22} X_{2}^{2}+\beta_{33} X_{3}^{2}
\end{aligned}
$$

where $Y$-predicted response of fermentation $X_{1}, X_{2}$ and $X_{3}$ are the coded settings for three factors $\beta_{0}$-value of fitted response at the center point of the design $\beta_{1}, \beta_{2}$, and $\beta_{3}$ linear coefficients $\beta_{12}, \beta_{13}$, and $\beta_{23}$-interaction coefficients $\beta_{11}, \beta_{22}$, and $\beta_{33}$-quadratic coefficients.

Emulsification index $\left(E_{24}\right)$

The emulsifying capacity was evaluated by an emulsification index $\left(E_{24}\right)$. The $E_{24}$ of culture samples was determined by adding $2 \mathrm{ml}$ of oil and $2 \mathrm{ml}$ of the cell-free broth to a test tube, vortexed at high speed for $2 \mathrm{~min}$, and allowed to stand for $24 \mathrm{~h}$. The $E_{24}$ index is given as percentage of the height of emulsified layer $(\mathrm{cm})$ divided by the total height of the liquid column $(\mathrm{cm})$. The percentage of emulsification index was calculated by using the following equation (Tabatabaee et al. 2005; Sarubbo et al. 2006).

$E_{24}=$ Height of emulsion formed $\times 100$ /total height of solution.

Extraction of biosurfactant

Initially, culture supernatant was adjusted to $\mathrm{pH}$ of 2.0 by adding $5 \mathrm{~mol} / \mathrm{H} \mathrm{H}_{2} \mathrm{SO}_{4}$ for precipitation of biosurfactant. The precipitates were extracted with two volumes of ethyl acetate. After vacuum evaporation of the solvents using rotary evaporator, crude biosurfactant was extracted 
Table 1 High and low levels of factors with coded settings by PBD

\begin{tabular}{llllllll}
\hline Trial & $\begin{array}{l}X_{1} \\
\text { Sawdust }(\mathrm{gm})\end{array}$ & $\begin{array}{l}X_{2} \\
\text { Groundnut husk }(\mathrm{g})\end{array}$ & $\begin{array}{l}X_{3} \\
\text { Glycerol }(\mathrm{ml})\end{array}$ & $\begin{array}{l}X_{4} \\
\text { Groundnut oil }(\mathrm{ml})\end{array}$ & $\begin{array}{l}X_{5} \\
\mathrm{pH}\end{array}$ & $\begin{array}{l}X_{6} \\
\text { Inoculum level (ml) }\end{array}$ & Surface tension (mN/m) \\
\hline R1 & $+1(10)$ & $+1(10)$ & $+1(3)$ & $+1(3)$ & $+1(9)$ & $+1(5)$ & 41.32 \\
R2 & $-1(5)$ & $+1(10)$ & $-1(1)$ & $+1(3)$ & $+1(9)$ & $+1(5)$ & 39.11 \\
R3 & $-1(5)$ & $-1(5)$ & $+1(3)$ & $-1(1)$ & $+1(9)$ & $+1(5)$ & 40.02 \\
R4 & $+1(10)$ & $-1(5)$ & $-1(1)$ & $+1(3)$ & $-1(5)+1(5)$ & 69.31 \\
R5 & $-1(5)$ & $+1(10)$ & $-1(1)$ & $-1(1)$ & $+1(9)-1(1)$ & 49.03 \\
R6 & $-1(5)$ & $-1(5)$ & $+1(3)$ & $-1(1)$ & $-1(5)+1(5)$ & 68.23 \\
R7 & $-1(5)$ & $-1(5)$ & $-1(1)$ & $+1(3)$ & $-1(5)-1(1)$ & 70.62 \\
R8 & $+1(10)$ & $-1(5)$ & $-1(1)$ & $-1(1)$ & $+1(9)$ & $-1(1)$ & 43.24 \\
R9 & $+1(10)$ & $+1(10)$ & $-1(1)$ & $-1(1)$ & $-1(5)+1(5)$ & 69.04 \\
R10 & $+1(10)$ & $+1(10)$ & $+1(3)$ & $-1(1)$ & $-1(5)-1(1)$ & 68.51 \\
R11 & $-1(5)$ & $+1(10)$ & $+1(3)$ & $+1(3)$ & $-1(5)$ & $-1(1)$ & 68.72 \\
R12 & $+1(10)$ & $-1(5)$ & $+1(3)$ & $+1(3)$ & $+1(9)$ & $-1(1)$ & 41.33 \\
\hline
\end{tabular}

R1-R12 represents twelve different fermentations

with pellet form. The yielded pellets were applied onto thin-layer chromatography (TLC). Solvent mixture used in this study was chloroform, methanol, and water (65:25:4, $\mathrm{V} / \mathrm{V} / \mathrm{V})$. Biosurfactant spots were detected by using orcinol reagent (Zhang Guo-liang et al. 2005).

Quantification of biosurfactant by orcinol method

The culture supernatant is acidified to $\mathrm{pH} 2$ with $5 \mathrm{~mol} / \mathrm{l}$ $\mathrm{H}_{2} \mathrm{SO}_{4}$ and kept at $4{ }^{\circ} \mathrm{C}$ overnight. Two hundred microliters of acidified culture supernatant was extracted three times with $1 \mathrm{ml}$ of diethyl ether. Then, fractions were pooled, dried, and resuspended in $1 \mathrm{ml}$ of $0.05 \mathrm{M}$ sodium bicarbonate. Two hundred microliters of sample was treated with $1.8 \mathrm{ml}$ of a orcinol solution $(100 \mathrm{mg}$ orcinol in $53 \% \mathrm{H}_{2} \mathrm{SO}_{4}$ and boiled for $20 \mathrm{~min}$ ). After cooling at room temperature for $15 \mathrm{~min}$, the readings are taken at $421 \mathrm{~nm}$. Biosurfactant concentration was calculated from standard curves prepared with 1-rhamnose and expressed as rhamnose equivalents (in $\mathrm{mg} / \mathrm{ml}$ ) (Chandrasekaran and BeMiller 1980; Koch et al. 1991).

\section{Determination of surface tension}

For surface tension measurements, $5 \mathrm{ml}$ of broth supernatant was transferred to a glass tube that was submerged in a water bath at a constant temperature $\left(28{ }^{\circ} \mathrm{C}\right)$. Surface tension was calculated by measuring the height reached by the liquid when freely ascended through a capillary tube (Munguia and Smith 2001). As control, non-inoculated broth was used, and the surface tension was calculated according to the following formula: $\gamma=\frac{r h \delta g}{2}$

$\gamma=$ surface $\quad$ tension $(\mathrm{mN} / \mathrm{m}) ; \quad d=$ density $\quad(\mathrm{g} / \mathrm{ml}) ;$ $g=$ gravity $\left(980 \mathrm{~cm} / \mathrm{s}^{2}\right) ; r=$ capillary radius $(0.05 \mathrm{~cm})$; $h=$ height of the liquid column $(\mathrm{cm})$.

Bacterial growth and dry cell weight

Cell growth was determined by monitoring the optical density of culture broth at $600 \mathrm{~nm}$. The biomass was determined from the cells after centrifugation of the culture broth at $10,000 \mathrm{rpm}(6,700 \mathrm{~g}) 4{ }^{\circ} \mathrm{C}$ for $10 \mathrm{~min}$. The dry cell weight (DCW) was obtained from the cell pellets by washing twice with distilled water and drying in hot air oven at $105^{\circ} \mathrm{C}$ for $24 \mathrm{~h}$ (Suwansukho et al. 2008).

Kinetic model for growth and glycolipid product

Logistic equation: The sigmoidal shape of batch growth of Pseudomonas aeruginosa can be given as

$\frac{\mathrm{d} X}{\mathrm{~d} t}=\mu X\left(1-\frac{X}{X_{\infty}}\right)$

where $\mu$ : specific growth rate, $X_{\infty}$ : maximum biomass concentration.

Logistic equations are a set of equations that characterize growth in terms of specific growth rate (Shuler and Kargi 2003). The integration of Eq. (2) with the boundary condition $X(0)=X_{0}$ yields the logistic curve.

$X=\frac{X_{0} \mathrm{e}^{\mu t}}{1-\frac{X_{0}}{X_{\infty}}\left(1-\mathrm{e}^{\mu t}\right)}$

The above equation can be written as follows: 
$\mu=\frac{1}{\bar{X}} \frac{\Delta X}{\Delta t} /\left(1-\frac{\bar{X}}{X_{\infty}}\right)$

$\bar{X}$ : Average biomass concentration.

Leudeking-Piret model: Bio-products are classified as growth associated, non-growth associated, and mixed growth associated metabolites based on their production during log or stationary phases of cell growth. The kinetics of rate of product formation $\left(r_{\mathrm{p}}\right)$, in batch culture was described by Leudeking-Piret model and was given as follows:

$r_{\mathrm{p}}=\frac{d p}{d t}=\alpha\left(r_{x}\right)+\beta x$

where $\alpha$-growth associated term; $\beta$-non-growth associated term.

The bio-product formation associated with exponential growth of Pseudomonas aeruginosa was modeled as

$r_{\mathrm{p}}=\frac{d p}{d t}=\alpha\left(r_{x}\right)$

A mixed growth associated product formation was modeled by the Eq. (8), and the product produced during stationary phase was modeled as follows:

$r_{\mathrm{p}}=\frac{\mathrm{d} p}{\mathrm{~d} t}=\beta x$

The above equation is rearranged to calculate $\alpha$ and $\beta$ by plotting a graph between $r_{\mathrm{p} / x}$ and $r_{x} / x$.

The product yield on biomass growth,

$Y_{P / X}=\frac{X-X_{0}}{P-P_{0}}$.

\section{Results}

In the present study, the screening of Pseudomonas aeruginosa 2297 was carried out using oil collapse and oil spreading techniques. It gave positive results for both oil collapse and oil spreading tests. The emulsification activities of the biosurfactant produced by Pseudomonas aeruginosa 2297 from different fermentation substrates and synthetic surfactants were tested with diesel, petrol, olive oil, and groundnut oil. When petrol and olive oil tested, maximum emulsification activity of $72.25 \pm 2.47$ and $59.23 \pm 0.19 \%$ was shown by biosurfactant produced from groundnut husk and coconut oil, respectively, used as a substrate and was comparable to all synthetic surfactants (Fig. 1). In diesel and groundnut oil, the synthetic surfactants (SDS) had the highest activity of $70.41 \pm 0.56$ and $62.31 \pm 0.28 \%$, respectively, compared to all biosurfactants (Fig. 1). From the quantification experiment, the highest biosurfactant production was observed in sawdust

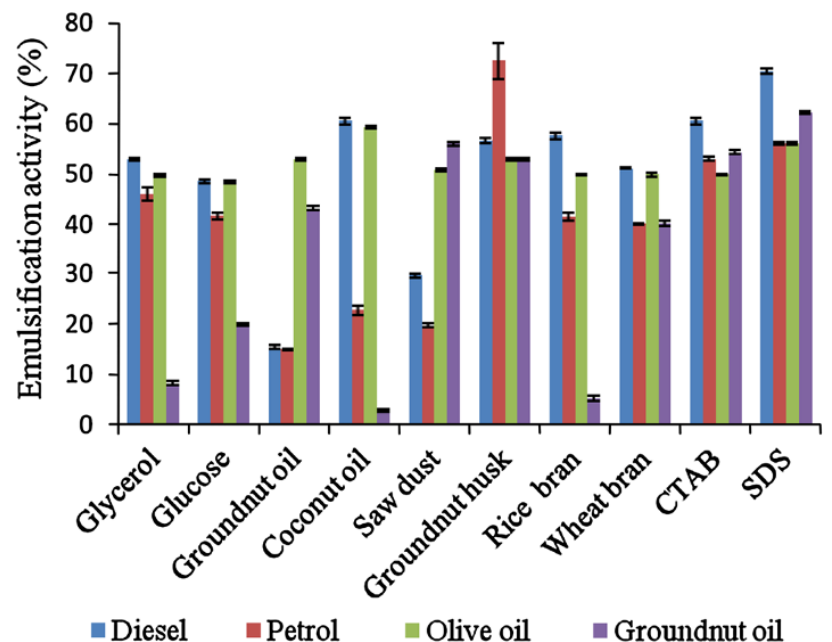

Fig. 1 Emulsification activity of different carbon and renewable sources from $P$. aeruginosa. *Values are represented as mean $\pm \mathrm{SD}$

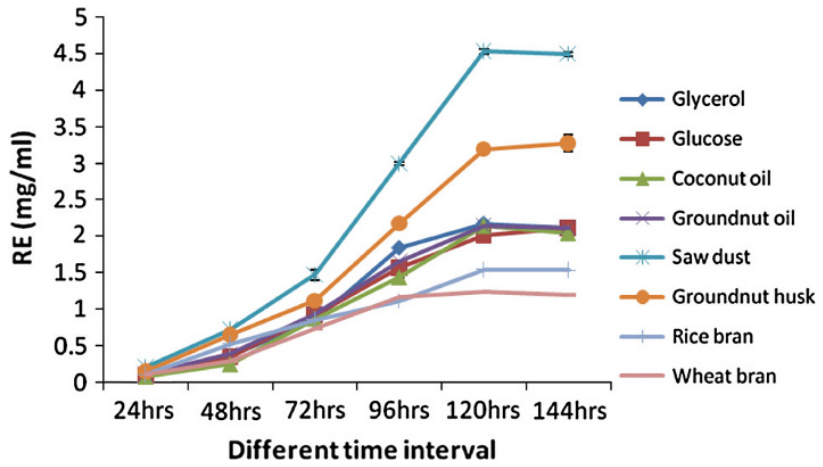

Fig. 2 Rhamnose equivalents of different carbon and renewable sources from $P$. aeruginosa. $*$ Values are represented as mean $\pm \mathrm{SD}$

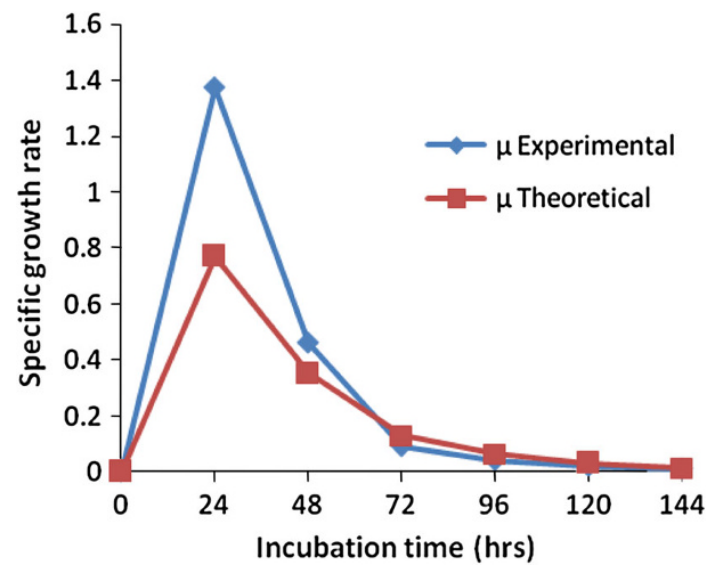

Fig. 3 Comparison of experimental and predicted specific growth rate of $P$. aeruginosa

with $4.53 \pm 0.03 \mathrm{mg} / \mathrm{ml}$ (Fig. 2) followed by groundnut husk and glycerol as substrates.

The biomass concentration on sawdust was used in the calculation of specific growth rate, and it was obtained as 


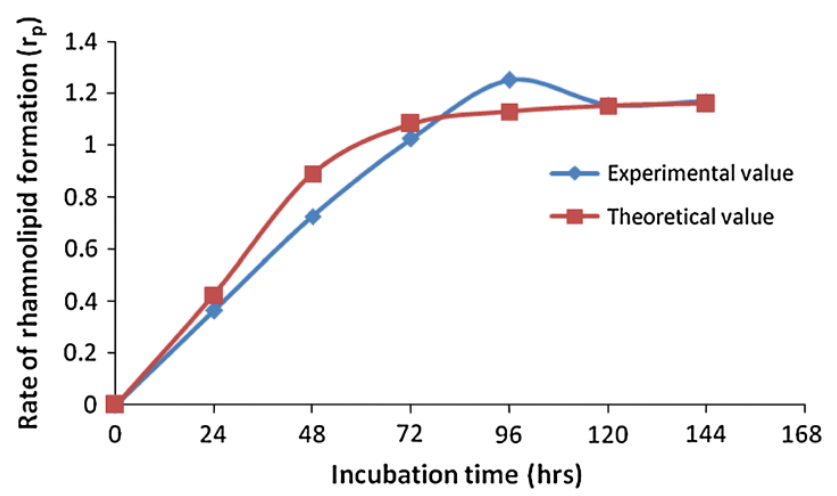

Fig. 4 Comparison of experimental and predicted rate of rhamnolipid formation $\left(r_{p}\right)$ of $P$. aeruginosa

1.12 day $^{-1}$, which would describe the most of the data. The lower value of specific growth rate $\left(0.04 \mathrm{~h}^{-1}\right)$ was observed on cheap substrate (sawdust). The variation in experimental and predicted specific growth rate with time was depicted in Fig. 3. Higher value of $F(11.14)$ and a very low value of $P(<0.01)$ indicate that the logistic equation was the best-fit growth model for the Pseudomonas aeruginosa 2297 growth on sawdust consumption (Supplementary Table 1).

Based on the data obtained on the biomass and biosurfactant concentrations, the growth rate $\left(r_{x}\right)$ and product formation $\left(r_{\mathrm{p}}\right)$ were calculated. The value of $\beta$ was obtained as 0.186 with the negligible $\alpha$ which was an indication of the bio-product was non-growth associated product. From the above results, it was noticed that the more amount of product was formed during the stationary phase of Pseudomonas aeruginosa 2297. The comparison of experimental and predicted rate of biosurfactant production was depicted (Fig. 4). The estimated value of product yield on biomass growth $\left(Y_{\mathrm{p} / x}\right)$ was $1.02 \mathrm{~g} / \mathrm{g}$. The significance of model was verified with analysis of variance given in Supplementary Table 2. The higher value of $F(13.19)$ and a very low value of $P(<0.001)$ indicated the best fit of model to the experimental data.

In PBD approach, six parameters including carbon sources (groundnut oil and glycerol), renewable sources (groundnut husk and sawdust), and other factors ( $\mathrm{pH}$ and inoculum level) were screened for biosurfactant production in 12 combinations with two test levels, and experiments were performed according to design matrix detailed in Table 1). From the PBD surface tension results, main effects were calculated at a confidence level of $95 \%$ and are summarized in Table 2. Box-Behnken design (BBD) was adopted to optimize the levels of three identified substrates. The individual and interactive effects were noticed at three levels $(-1,0$, and +1$)$ of variables, and detailed design was given in Table 3 . The response surface plot was represented as 3D plot with axes $\mathrm{pH}$, sawdust, and
Table 2 Identification of significant substrates using PBD

\begin{tabular}{lrr}
\hline Factor & Main effect & \multicolumn{1}{c}{$t$ stat } \\
\hline Sawdust & 0.91 & 0.66 \\
Groundnut husk & -0.91 & -0.66 \\
Glycerol & 0.18 & 0.13 \\
Groundnut oil & 0.56 & 0.41 \\
$\mathrm{pH}$ & -12.21 & -8.86 \\
Inoculum & -2.36 & -1.71 \\
\hline
\end{tabular}

Table 3 Three levels of substrates with actual and coded values and Box-Behnken experimental design matrix with experimental and predicted values of biosurfactant production

\begin{tabular}{llcclc}
\hline Trial & $\begin{array}{l}\mathrm{pH} \\
\left(X_{1}\right)\end{array}$ & $\begin{array}{l}\text { Glycerol } \\
\left(X_{2}\right)(\mathrm{ml})\end{array}$ & $\begin{array}{l}\text { Sawdust } \\
\left(X_{3}\right)(\mathrm{g})\end{array}$ & $\begin{array}{l}\text { Surface } \\
\text { tension } \\
(\mathrm{mN} / \mathrm{m}), \\
\text { experimental }\end{array}$ & $\begin{array}{l}\text { Surface } \\
\text { tension } \\
(\mathrm{mN} / \mathrm{m}) \\
\text { predicted }\end{array}$ \\
\hline 1 & $-1(5)$ & $-1(1)$ & $0(7.5)$ & 0 & 5.28 \\
2 & $-1(5)$ & $+1(3)$ & $0(7.5)$ & 0 & 5.43 \\
3 & $+1(9)$ & $-1(1)$ & $0(7.5)$ & 69.32 & 74.52 \\
4 & $+1(9)$ & $+1(3)$ & $0(7.5)$ & 58.91 & 52.63 \\
5 & $-1(5)$ & $0(2)$ & $-1(5)$ & 0 & 0.65 \\
6 & $-1(5)$ & $0(2)$ & $+1(10)$ & 0 & 0.25 \\
7 & $+1(9)$ & $0(2)$ & $-1(5)$ & 62.33 & 62.55 \\
8 & $+1(9)$ & $0(2)$ & $+1(10)$ & 62.33 & 61.65 \\
9 & $0(7)$ & $-1(1)$ & $-1(5)$ & 69.04 & 63.78 \\
10 & $0(7)$ & $-1(1)$ & $+1(10)$ & 68.54 & 62.45 \\
11 & $0(7)$ & $+1(3)$ & $-1(5)$ & 39.23 & 62.08 \\
12 & $0(7)$ & $+1(3)$ & $+1(10)$ & 41.31 & 63.76 \\
13 & $0(7)$ & $0(2)$ & $0(7.5)$ & 62.33 & 62.33 \\
14 & $0(7)$ & $0(2)$ & $0(7.5)$ & 62.33 & 62.33 \\
15 & $0(7)$ & $0(2)$ & $0(7.5)$ & 62.33 & 62.33 \\
\hline
\end{tabular}

$R^{2}(\operatorname{adj})=93.36 \% ; R^{2}=97.63 \%$

glycerol at three levels of $-1,0$, and 1 (Fig. 5). The contour plots depicted interactions of two variables with fixed value of variable at its control level (Fig. 6). The outcomes of Table 3 revealed that the factors $X_{1}, X_{2}$, and $X_{1}^{2}$ $(* P<0.05)$ were significant, but the remaining terms were not significant (Supplementary Table 3 ). Computed $F$ value (22.89) and $P<0.001$ was an indication of fitness of polynomial model (Table 4$)$.

\section{Discussion}

Selection of oil collapse and oil spreading methods was due to their strong advantages including simplicity, low cost, quick implementation, and use of relatively common equipment that is accessible in almost every microbiological laboratory. However, as expected, these methods are 
Fig. 5 Quadratic surface model for biosurfactant production by P. aeruginosa
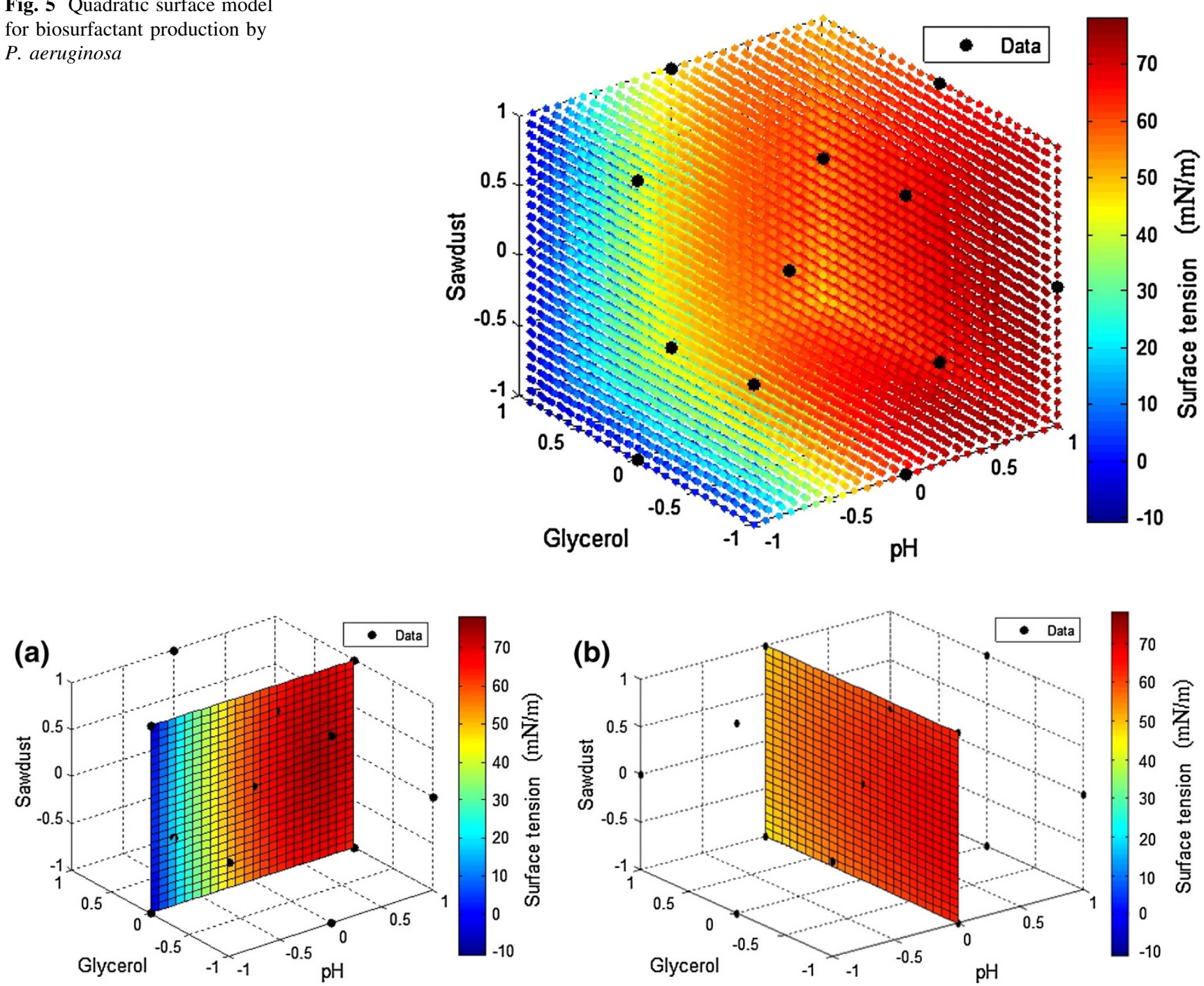

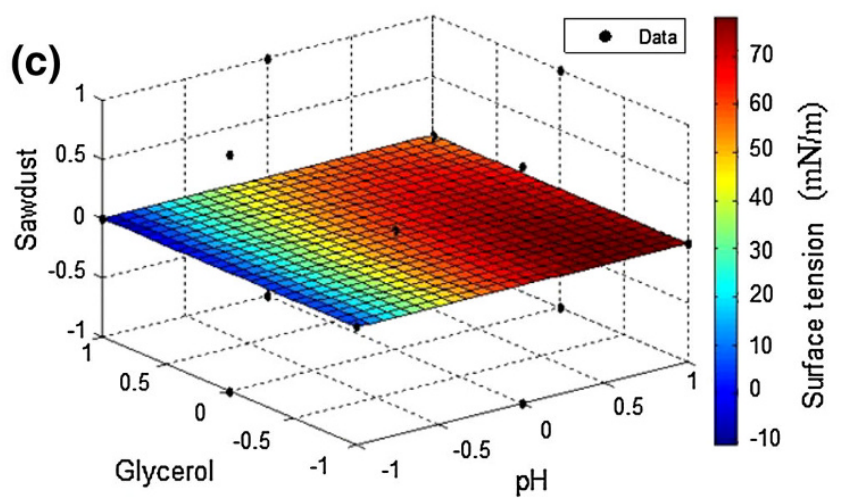

Fig. 6 a Interaction of $\mathrm{pH}$ and sawdust while glycerol at its control value, $\mathbf{b}$ interaction of glycerol and sawdust while $\mathrm{pH}$ at its control value, c interaction of glycerol and $\mathrm{pH}$ while sawdust at its control value

not perfect or flawless. The drop collapse method depends on the principle that a drop of liquid containing a biosurfactant collapses and spreads over the oily surface. There is a direct relationship between the diameter of the sample and concentration of the biosurfactant, and in contrast, the drop lacking biosurfactant remains beaded due to the hydrophobicity of the oil surface that cause aggregation of droplets (Youssef et al. 2004); Bodour and Miller-Maier 
Table 4 Analysis of variance for the fitted second-order regression model for surface tension

\begin{tabular}{lrrrrr}
\hline Source & Df & \multicolumn{1}{l}{ SS } & \multicolumn{1}{l}{ MS } & \multicolumn{1}{l}{$F$} & $P$ value \\
\hline Regression & 9 & $11,262.39$ & $1,251.38$ & 22.89 & $<0.001$ \\
Residual & 5 & 273.39 & 54.68 & & \\
Total & 14 & $11,535.78$ & & & \\
\hline
\end{tabular}

$D f$ degrees of freedom, $S S$ sum of squares, $M S$ mean of squares, $F$ Fischer's test value, $P$ value probability value

1998; Christofi and Ivshina 2002; Bodour et al. 2003; Tugrul and Cansunar 2005; Krepsky et al. 2007), but this method is not sensitive in detecting low levels of biosurfactant production. The emulsification index range of 7.8-63.3 \% EA from biosurfactant was reported on kerosene (Techaosi et al. 2007). In Rhodococcus strain, emulsification activity of $63 \%$ was reported using sunflower frying oil as substrate (Sadouk et al. 2008).

The Pseudomonas aeruginosa 2297 was extensively utilizes the renewable sources. During the growth of Pseudomonas aeruginosa, it produces surface-active compounds, which were measured as rhamnose equivalents (RE). Similar type of result was reported by Pseudomonas strain (Deziel et al. 1996). Biosurfactant production, like cell growth, depends on the availability of the substrate. Agro-industrial wastes are considered as the promising substrate for biosurfactant production and can alleviate many processing industrial waste management problems (Makkar et al. 2011). In the present TLC studies, we found that the Pseudomonas aeruginosa have shown two spots, which resembles the presence of two types of biosurfactants produced by used organisms, and similar results were observed by Koch et al. (1991) and Matsufuji et al. (1997) with Pseudomonas aeruginosa.

According to Sastoque-Cala et al. (2010), the specific rate of $0.109 \mathrm{~h}^{-1}$ was obtained by using MMS broth from Pseudomonas fluorescence. Regarding the production rate, the Leudeking and Piret model was used to describe this parameter, as it is versatile for fitting product formation data obtained from several fermentation processes (Bailey and Ollis 1986). According to the Rashedi et al. (2005), the maximum yield of rhamnolipid $\left(Y_{\mathrm{p} / x}\right)$ from Pseudomonas aeruginosa was $0.21 \mathrm{~g} / \mathrm{g}$.

A suitable medium was also formulated through statistical optimization methodology since it has various advantages of being rapid and reliable in short listing of nutrients at varying concentrations leading to significant reduction in the total number of experiments. Two sequential steps of statistical approach such as PlackettBurman design (PBD) and response surface methodology (RSM) were performed to design the optimized production medium for biosurfactant from Pseudomonas aeruginosa.
When additional factors are to be investigated, Plackett-Burman method may be adopted to find the variables influencing the metabolite production (Plackett and Burman 1944). This technique allows for the evaluation of ' $n-1$ ' variables in ' $n$ ' experiments at high and low levels, and ' $n$ ' must be the multiple of 4 . Each row in the design matrix represents one experimental run, and each column represents the high and low values of one factor. It requires that the frequency of each level of a variable in a given column should be equal. Once the data are obtained for each trial, statistical analysis can be performed to evaluate and rank factors by their degree of impact on the fermentation process. This ranking begins with the calculation of main effect and probability value of each factor. The main effect of the factor refers to the change in response over the entire range $(-1$ to +1$)$.

For a variable $X$,

Main effect $=\frac{\sum X(H)}{n / 2}-\frac{\sum X(L)}{n / 2}$

where $\Sigma X(H)$ : sum of high values of variable ' $X$ ' in one experimental run $\Sigma X(L)$ : sum of low values of variable ' $X$ ' in one experimental run $n$ : number of experimental runs

Software programs such as Microsoft Excel and MATLAB are used to calculate the main effects and $P$ (probability) values of variables. A large estimate, either positive or negative, indicates that a factor has a large impact on metabolite productivity, while an estimate close to zero means that a factor has little or no effect. Generally, probability value $<0.01$ for a factor is considered as significant factor for the response of fermentation.

This statistical design is described by a first-order linear model as follows:

$Y_{\mathrm{S}}=\beta_{0}+\sum_{i=1}^{n} \beta_{i} X_{i}$

$Y_{\mathrm{S}}$ : surface tension, $\beta_{i}$ : linear coefficients, $X_{i}$ : factors.

The confidence level of components below $95 \%$ in biosurfactant production was considered insignificant. Here, positive effect means reduction in surface tension, and negative effect means increase in surface tension. Hence, the effect for each component was considered as opposite from calculated values, i.e., lower surface tension means positive effect, and higher value means negative effect.

Of the tested variables, the positive effects on biosurfactant production have shown by sawdust, groundnut oil, and glycerol, while the negative impacts had given by $\mathrm{pH}$, inoculums size, and groundnut husk. Initial $\mathrm{pH}$ of fermentation medium has got the highest impact on the surface tension. Significance of the present experimental could 
be validated through analysis of variance $(P$ value $<0.001)$. Proposed linear model was as follows:

$$
\begin{aligned}
Y_{\mathrm{S}}= & 56.841+0.908 X_{1}-0.908 X_{2}+0.175 X_{3} \\
& +0.558 X_{4}-12.802 X_{5}-2.358 X_{6}
\end{aligned}
$$

Based on the main effects $\mathrm{pH}$, sawdust and glycerol have profound effect on the biosurfactant production, and the exact optimal values of the individual factors are still unknown but can be optimized by RSM.

RSM is the process of adjusting variables toward the optimum response of fermentation. A second-order polynomial equation, fitted to data by multiple regression procedure, resulted in quadratic model, and it was given by Eq. 1 .

$$
\begin{aligned}
Y= & \beta_{0}+\beta_{1} X_{1}+\beta_{2} X_{2}+\beta_{3} X_{3}+\beta_{12} X_{1} X_{2}+\beta_{13} X_{1} X_{3} \\
& +\beta_{23} X_{2} X_{3}+\beta_{11} X_{1}^{2}+\beta_{22} X_{2}^{2}+\beta_{33} X_{3}^{2}
\end{aligned}
$$

where $Y$-predicted response of fermentation $X_{1}, X_{2}$ and $X_{3}$ are the coded settings for three factors $\beta_{0}$-value of fitted response at the center point of the design $\beta_{1}, \beta_{2}$, and $\beta_{3}-$ linear coefficients $\beta_{12}, \beta_{13}$, and $\beta_{23}$-interaction coefficients $\beta_{11}, \beta_{22}$, and $\beta_{33}$-quadratic coefficients.

An optimum combination of variables (pH: 7.37, sawdust: $7.656 \mathrm{~g}$, and glycerol: $1.5 \mathrm{ml}$ ) was achieved through predicted plot of full quadratic model with surface tension of $70 \pm 40 \mathrm{mN} / \mathrm{m}$. To confirm the coefficients of secondorder polynomial model by regression coefficient and analysis of variance (ANOVA), biosurfactant production was performed and the proposed model was written as follows:

$$
\begin{aligned}
Y= & 62.3+31.6 X_{1}-8.425 X_{2}+0.2 X_{3}-2.6 X_{1} X_{2} \\
& +0.65 X_{2} X_{3}-26.8 X_{1}^{2}-3.45 X_{2}^{2}-4.35 X_{3}^{2}
\end{aligned}
$$

Results obtained from Table 3 illustrated that the factors $X_{1}, X_{2}$, and $X_{1}^{2}(* P<0.05)$ were significant and the rest were not significant (Supplementary Table 3 ). Computed $F$ value (22.89) and $P<0.001$ was an indication of fitness of polynomial model (Table 4). The multiple correlation coefficient $\left(R^{2}\right)$ was calculated as $97.63 \%$. This indicates that the second-order polynomial model could explain $97.63 \%$ of variability in the response, and only $2.37 \%$ of the total variations were not explained by the model. The adjusted $R^{2}(93.36 \%)$ and predicted $R^{2}(97.63 \%)$ were suggesting a high significance model used for analyzing the data.

Abalos et al. (2002) reported the utilization of response surface methodology to optimize the culture media for the production of rhamnolipids by Pseudomonas aeruginosa AT10. Similarly, Joshi et al. (2007) also reported the statistical optimization of medium components for the production of biosurfactant by Bacillus licheniformis K51. According to Joshi et al. (2007), Plackett-Burman and
Box-Behnken designs are very effective statistical tools to improving biosurfactant production.

\section{Conclusion}

In the present study, $P$. aeruginosa 2297 has showed good screening, emulsification, and surface-active properties. In the initial screening optimum process for carbon and renewable sources, sawdust, groundnut husk, groundnut, and glycerol were the best optimized substrates for biosurfactant production. The logistic equation and Leudeking-Piret models would fit to the growth of Pseudomonas aeruginosa on sawdust consumption and biosurfactant production. The statistical analysis of coefficient in Plackett-Burman design experiments demonstrates that $\mathrm{pH}$, sawdust, and glycerol showed profound effect on the biosurfactant production. Optimization of these three selected variables while keeping the rest of the factors at their low levels through a Box-Behnken design shows maximum predicted biosurfactant production using $\mathrm{pH}$ : 7.37, sawdust: $7.656 \mathrm{~g}$, and glycerol: $1.5 \mathrm{ml}$.

Acknowledgments The authors are thankful to university authorities of Sri Venkateswara University, Tirupati, Andhra Pradesh, India, for providing laboratory facilities.

Conflict of interest We are declaring that there is no conflict of interests regarding the publication of this article.

Open Access This article is distributed under the terms of the Creative Commons Attribution License which permits any use, distribution, and reproduction in any medium, provided the original author(s) and the source are credited.

\section{References}

Abalos A, Maximo F, Manresa MA, Bastida J (2002) Utilization of response surface methodology to optimize the culture media for the production of rhamnolipids by Pseudomonas aeruginosa AT 10. J Chem Technol Biotechnol 77(7):777-784

Al-Araji L, Rahman R, Basri M, Salleh A (2007) Optimisation of rhamnolipids produced by Pseudomonas aeruginosa 181 using response surface modeling. Ann Microbiol 57(4):571-575

Bailey JE, Ollis DF (1986) Biochemical engineering fundamentals. McGraw-Hill International, London

Bodour AA, Miller-Maier RM (1998) Application of a modified dropcollapse technique for surfactant quantification and screening of biosurfactant producing microorganisms. J Microbiol Meth 32(3):273-280

Bodour AA, Drees KP, Maier RM (2003) Distribution of biosurfactant-producing bacteria in undisturbed and contaminated arid southwestern soils. Appl Environ Microbiol 69(6):3280-3287

Box GEP (1952) Multi-factor designs of first order. Biometrika 39(1-2):49-57

Camilios D, Meira JA, De Araujo JM, Mitchell DA, Krieger N (2008) Optimization of the production of rhamnolipids by Pseudomonas 
aeruginosa UFPEDA 614 in solid-state culture. Appl Microbiol Biotech 81(3):441-448

Chandrasekaran EV, BeMiller JN (1980) Constituent analysis of glycosaminoglycans. In: Whistler RL (ed) Methods in carbohydrate chemistry. Academic press Inc., New York, pp 89-96

Christofi N, Ivshina IB (2002) Microbial surfactants and their use in field studies of soil remediation. J Appl Microbiol 93(6):915929

Deziel E, Paquette G, Villemur R, Lepine F, Bisaillion JG (1996) Biosurfactant production by a soil Pseudomonas strain growing on polycyclic aromatic hydrocarbons. Appl Environ Microbiol 62(6): 1908-1912

Joshi S, Yadav S, Nerurkar A, Desai AJ (2007) Statistical optimization of medium components for the production of biosurfactant by Bacillus licheniformis K51. J Microbiol Biotechnol 17(2):313-319

Koch AK, Kappeli O, Feichter A, Reiser J (1991) Hydrocarbon assimilation and biosurfactant production in Pseudomonas aeruginosa mutants. J Bacteriol 173(13):4212-4219

Krepsky N, Da Silva FS, Fontana LF, Crapez M (2007) Alternative methodology for isolation of biosurfactant-producing bacteria. Braz J Biol 67(1):117-124

Lotfy WA, Ghanem KM, El-Helow ER (2007) Citric acid production by a novel Aspergillus niger isolate: II. Optimization of process parameters through statistical experimental designs. Bioresour Technol 98(18):3470-3477

Maier RM, Soberon-Chavez G (2000) Pseudomonas aeruginosa rhamnolipids: biosynthesis and potential applications. Appl Microbiol Biotech 54(5):625-633

Makkar RS, Cameotra SS, Banat IM (2011) Advances in utilization of renewable substrates for biosurfactant production. AMB Express $1: 1-19$

Matsufuji M, Nakata K, Yoshimoto A (1997) High production of rhamnolipids by Pseudomonas aeruginosa growing on ethanol. Biotechnol Lett 19(12):1213-1215

Montgomery DC (1997) Response surface methods and other approaches to process optimization. In: Montgomery DC (ed) Design and analysis of experiments. Wiley, New York, pp 427-510

Mukherjee S, Das P, Sen R (2006) Towards commercial production of microbial surfactants. Trends Biotech 24(11):509-515

Mulligan CN (2005) Environmental application for biosurfactants. Environ Pollut 133(2):183-198

Munguia T, Smith CA (2001) Surface tension determination through capillary rise and laser diffraction patterns. J Chem Educ 78(3):343-344

Perfumo A, Rancich I, Banat IM (2010) Possibilities and challenges for biosurfactants use in petroleum industry. Adv Exp Med Biol 672:135-145
Plackett RL, Burman JP (1944) The design of optimum multifactorial experiments. Biometrika 33(4):305-325

Rashedi H, Mazaheri Assadi M, Bonakdarpour B, Jamshidi E (2005) Environmental importance of rhamnolipid production from molasses as a carbon source. Int $\mathrm{J}$ Enviorn Sci Technol 2(1):59-62

Sadouk G, Hacene H, Tazerouti A (2008) Biosurfactants production from low cost substrate and degradation of diesel oil by a Rhodococcus strain. Oil Gas Sci Technol 63(6):747-753

Sarubbo LA, de Luna JM, de Campos-Takaki GM (2006) Production and stability studies of the bioemulsifiers obtained from a strain of Candida glabrata UCP 1002. Electron J Biotechol 9(4):400-406

Sastoque-Cala L, Cotes-Prado AM, Rodríguez-Vázquez R, PedrozaRodríguez AM (2010) Effect of nutrients and fermentation conditions on the production of biosurfactants using rhizobacteria isolated from fique plants. Universitas Scientiarum 15(3):251-264

Shuler ML, Kargi F (2003) A text book of bioprocess engineeringbasic concepts, chapter 6, 2nd edn. Pearson Education, pp $175-177$

Suwansukho P, Rukachisirikul V, Kawai F, Aran H-K (2008) Production and applications of biosurfactant from Bacillus subtilis MUV4. Songklanakarin J Sci Technol 30:87-93

Tabatabaee A, Assadi MM, Noohi AA, Sajadian VA (2005) Isolation of biosurfactant producing bacteria from oil reservoirs. Iran $\mathbf{J}$ Environ Health Sci Eng 2(1):6-12

Tanyildizi MS, Ozer D, Elibol M (2005) Optimization of $\alpha$-amylase production by Bacillus sp. using response surface methodology. Process Biochem 40(7):2291-2296

Techaosi S, Leelapornpisid P, Santiarwarn D, Lumyong S (2007) Preliminary screening of biosurfactant-producing microorganisms isolated from hot spring and garages in Northern Thailand. KMITL Sci Technol J 7(S1):38-43

Tugrul T, Cansunar E (2005) Detecting surfactant-producing microorganisms by the drop-collapse test. World J Microbiol Biotechnol 21(6-7):851-853

Wei YH, Lai HC, Chen SY, Yeh MS, Chang JS (2004) Biosurfactant production by Serratia marcescens SS-1 and its isogenic strain SMdeltaR defective in SpnR, a quorum-sensing LuxR family protein. Biotech Lett 26(10):799-802

Youssef NH, Duncan KE, Nagle DP, Savage KN, Knapp RM, McInerney MJ (2004) Comparison of methods to detect biosurfactant production by diverse microorganism. J Microbiol Method 56(3):339-347

Zhang G-L, Wu Y-T, Qian X-P, Meng Q (2005) Biodegradation of crude oil by Pseudomonas aeruginosa in the presence of rhamnolipids. J Zhejiang Univ Sci B 6(8):725-730 